\title{
Fungos Associados a Sementes de Cevadilha Vacariana (Bromus auleticus) Coletadas nas Plantas e no Solo
}

\author{
Gustavo M. Silva', Manoel S. Maia', Carlos Otávio C. Moraes², Renato B. Medeiros³, \\ Clarissa S. Silva ${ }^{4} \&$ Denise D. Pereira ${ }^{4}$
}

\begin{abstract}
${ }^{1}$ Departamento de Fitotecnia, Faculdade de Agronomia Eliseu Maciel, Universidade Federal de Pelotas, Cx. Postal 354,

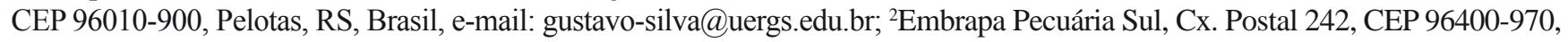
Bagé, RS, Brasil; ${ }^{3}$ Departamento de Meteorologia e Plantas Forrageiras, Universidade Federal do Rio Grande do Sul, Porto Alegre, RS, Brasil; ${ }^{4}$ Instituto Biotecnológico de Reprodução Vegetal, Universidade da Região da Campanha, Rua Flores da Cunha 310, CEP 96400-350, Bagé, RS, Brasil
\end{abstract}

Autor para correspondência: Gustavo M. Silva

SILVA, G.M., MAIA, M.S., MORAES, C.O.C., MEDEIROS, R.B., SILVA, C.S. \& PEREIRA, D.D. Fungos associados a sementes de cevadilha vacariana (Bromus auleticus) coletadas nas plantas e no solo. Fitopatologia Brasileira 32:353-357. 2007.

\section{RESUMO}

A espécie Bromus auleticus é uma gramínea perene nativa, com potencial para produção de forragem no outonoinverno, período de maior carência alimentar dos rebanhos bovino e ovino do sul do Brasil. O objetivo deste trabalho foi verificar a presença de microorganismos associados a sementes de $B$. auleticus, em função do momento de coleta, na planta e no solo. Os trabalhos de campo foram conduzidos na Embrapa Pecuária Sul, Bagé, estado do Rio Grande do Sul, em área semeada no ano de 1995. Em novembro de 2002 foram colhidas manualmente as panículas de 30 plantas representativas da população, das quais foram separadas aleatoriamente 900 sementes cheias. De outra forma, na mesma área experimental, realizaram-se coletas de solo nos primeiros dias dos meses de janeiro, fevereiro, março e abril, das quais foram separadas manualmente 200, 300, 200 e 60 sementes, respectivamente. Todas as sementes foram analisadas para sanidade utilizandose o método do papel de filtro (Blotter test), com incubação a $20^{\circ} \mathrm{C}, 12$ horas de luz, por um período de sete dias. Ocorreram vários fungos, principalmente Alternaria spp., associados a sementes de $B$. auleticus que ainda estavam presas à planta-mãe, com uma tendência de diminuição dessa contaminação após o desprendimento natural. Foi observada uma alta incidência do fungo Trichoderma em sementes coletadas do solo, provavelmente constituindo uma associação benéfica entre essas espécies. Estima-se que o fungo Trichoderma seja antagônico a outros fungos potencialmente patogênicos a sementes de Bromus auleticus, como Alternaria spp.

Palavras-chave adicionais: pastagem, forrageira, fungos, Trichoderma.

\begin{abstract}
Fungi associated with Bromus auleticus seeds collected from plants and soil

Bromus auleticus is a native perennial grass, with potential to produce forage in the autumn-winter, a period when animal feed is scarce in the south of Brazil. The objective of this work was to verify microorganisms associated with seeds of $B$. auleticus, in function of the moment of collection, in the plant and in the soil. Field studies were conducted in "Embrapa Pecuária Sul”, Bagé - state of Rio Grande do Sul, in an area sowed in 1995. Panicles of thirty representative plants were harvested in November, 2002, obtaining 900 seeds. Following another procedure, in the same experimental area, soil samples were collected in the first days of January, February, March and April; 200, 300, 200 and 60 seeds were thus obtained, respectively. All seeds were analyzed by the blotter test, with incubation at $20^{\circ} \mathrm{C}, 12$ hours of light, for a period of seven days. Several fungi were observed, mainly Alternaria spp., associated with seeds of B. auleticus that were still attached to the mother plant. There was a tendency for that contamination to decrease after natural detachment. A high incidence of Trichoderma was also observed in seeds of B. auleticus present in the soil, probably constituting a beneficial association between these species. It is considered that Trichoderma may be antagonistic to other fungi that are potentially pathogenic to seeds of Bromus auleticus, such as Alternaria spp.
\end{abstract}

Additional keywords: pasture, forage, fungi, Trichoderma.

Uma das principais atividades primárias da região sul do Brasil é a pecuária de corte, com importância econômica destacada para o desenvolvimento da referida região. Contudo, as pastagens naturais, que são a base alimentar

Parte da Tese de Doutorado do primeiro autor. Universidade Federal de Pelotas. Pelotas RS. 2004. dos rebanhos bovino e ovino, apresentam uma produção de forragem baixa no período de outono-inverno, em função das condições climáticas adversas ao desenvolvimento das plantas (Barcellos et al., 2002).

Bromus auleticus Trin. ex Nees, também chamado cevadilha vacariana, é uma gramínea perene de clima temperado, nativa da região sul do Brasil, Uruguai e Argentina (Garcia, 1988). É uma espécie com potencial 
forrageiro, já que têm mostrado ser bem aceita pelos animais, e apresenta uma grande produção de forragem com boa qualidade no período de maior carência alimentar do rebanho sul-brasileiro (Oliveira \& Moraes, 1993).

A produção de sementes sempre é um fator de grande importância para a domesticação e utilização em cultivo de uma espécie, mesmo tratando-se de uma planta com potencial forrageiro. Bromus auleticus apresenta capacidade para produzir grande quantidade de sementes viáveis (Boggiano \& Zanoniani, 2001). Os microorganismos constituem um fator fundamental em termos de qualidade de sementes, e também limitante da produção, como é o caso de bacterioses, viroses e doenças fúngicas (Lucca Filho, 2003). Pouco foi pesquisado até o momento com relação à sanidade de sementes de Bromus auleticus.

Um aspecto importante para a implantação e persistência de uma pastagem via ressemeadura natural, é a interação entre as sementes e os microorganismos do solo. Para que uma semente persista enterrada um longo tempo, deve ser resistente a uma quantidade de patógenos edáficos, que constituem uma das principais causas de mortalidade pré-germinativa. Os microorganismos do solo atuam mediante enzimas, como as celulases, proteases e nucleases, e com toxinas que destroem as membranas e causam danos irreversíveis, inclusive a morte das sementes. As relações entre sementes e microorganismos do solo ainda estão pouco estudadas (Marañón, 1995; Baskin \& Baskin, 1998).

A principal defesa das sementes é a cobertura protetora, que supõe uma barreira mecânica ao ataque de fungos. Além disso, as sementes podem apresentar compostos antifúngicos, como flavonóides e taninos, e transportar bactérias ou fungos que são antagonistas dos microorganismos patogênicos do solo (Baskin \& Baskin, 1998). O objetivo deste trabalho foi verificar a presença de fungos associados a sementes de Bromus auleticus, em função do momento de coleta, na planta e no solo.

Os trabalhos de campo foram conduzidos na Embrapa Pecuária Sul, em Bagé RS, em área semeada com Bromus auleticus no ano de 1995, o qual se manteve, desde então, como espécie dominante. Segundo informações registradas do Banco Ativo de Germoplasma - BAG, esse material constitui o acesso Limoeiro, proveniente da região de Bagé$\mathrm{RS}$, que tem sido identificado como um dos mais produtivos presentes no BAG. A região apresenta clima mesotérmico subtropical com precipitação pluvial média anual de 1300 $\mathrm{mm}$, regularmente distribuídos durante $\mathrm{o}$ ano. A temperatura média anual é de $17,6^{\circ} \mathrm{C}$, com extremas de $-4^{\circ} \mathrm{C}$ e $41^{\circ} \mathrm{C}$ e ocorrência de geadas principalmente nos meses de junho a agosto (Oliveira \& Moraes, 1993).

Em novembro de 2002 foram colhidas manualmente as panículas de 30 plantas representativas da população, que apresentavam pelo menos cinco perfilhos reprodutivos. O material secou naturalmente em local arejado e depois foi conduzido até o Laboratório de Patologia de Sementes do Departamento de Fitossanidade, Faculdade de Agronomia Eliseu Maciel, Universidade Federal de Pelotas. As panículas foram trilhadas e separaram-se, aleatoriamente, 900 sementes para condução do teste de sanidade.

De outra forma, na mesma área experimental, realizaram-se coletas mensais de solo, com trado cilíndrico (10 cm de diâmetro e $5 \mathrm{~cm}$ de profundidade). As coletas foram realizadas nos primeiros dias dos meses de janeiro, fevereiro, março e abril de 2003, pois é o período do ano de maior depósito de sementes no solo, e maior fluxo germinativo. Cada coleta constou de 21 sub-amostras, que foram misturadas e secadas naturalmente em local arejado. A amostragem foi sistemática, ou seja, a primeira amostra selecionada ao acaso e as demais a intervalos regulares, na forma de "W" (Kenkel et al., 1989). Procedeu-se à separação manual das sementes de Bromus auleticus presentes no solo, as quais também foram submetidas ao teste de sanidade. $\mathrm{O}$ número de sementes utilizado dependeu da quantidade de sementes encontrada nas amostras de solo, avaliando-se 200, 300, 200 e 60 sementes em janeiro, fevereiro, março e abril, respectivamente. Nos demais meses, não foi encontrada quantidade suficiente de sementes para análise. Com esses procedimentos, pretendeu-se estimar a sanidade antes e depois do degrane natural, em cinco momentos distintos da vida das sementes.

O método utilizado para o teste de sanidade foi o papel-de-filtro (Blotter Test), conforme as normas da ISTA (1993). As sementes foram colocadas sobre três camadas de papel-filtro, em caixas plásticas tipo "gerbox", sendo utilizadas 50 sementes por caixa. Após, procedeu-se a incubação à temperatura de aproximadamente $20^{\circ} \mathrm{C}$ e regime luminoso diário de doze horas, por um período de sete dias. A seguir, as sementes foram examinadas, individualmente, com auxílio de microscópio estereoscópio com aumento de até 60x. Quando necessário, foram realizadas preparações microscópicas para a identificação dos fungos em microscópio composto.

Para o procedimento de análise estatística dos dados, foi utilizado o programa MULTIV versão 2.1.1 (Pillar, 2001). Considerou-se o levantamento sujeito à análise estatística multivariada, em função de atributos complexos que definiriam, ou não, padrões estruturais no tempo. Assim, cada época de coleta constituiu uma unidade amostral; e os percentuais dos diferentes fungos encontrados nas sementes foram as variáveis que caracterizaram as unidades amostrais. Utilizou-sea distância euclidiana como medida de semelhança entre as unidades amostrais. A análise de agrupamentos foi realizada pelo método de ligação simples; e para observar a existência de um padrão de distribuição das unidades amostrais, foi utilizada a ordenação multidimensional, através do método de coordenadas principais.

A análise de agrupamentos evidenciou significância para partições em dois e três grupos $(\alpha=0,1)$ (Figura 1 ). Contudo, a partição em dois grupos apresentou-se mais significativa. Na Figura 2, tem-se o diagrama de dispersão de pontos, com a identificação dos grupos estabelecidos através da análise de agrupamentos. De acordo com os autovalores obtidos pela análise de coordenadas principais, constata-se 


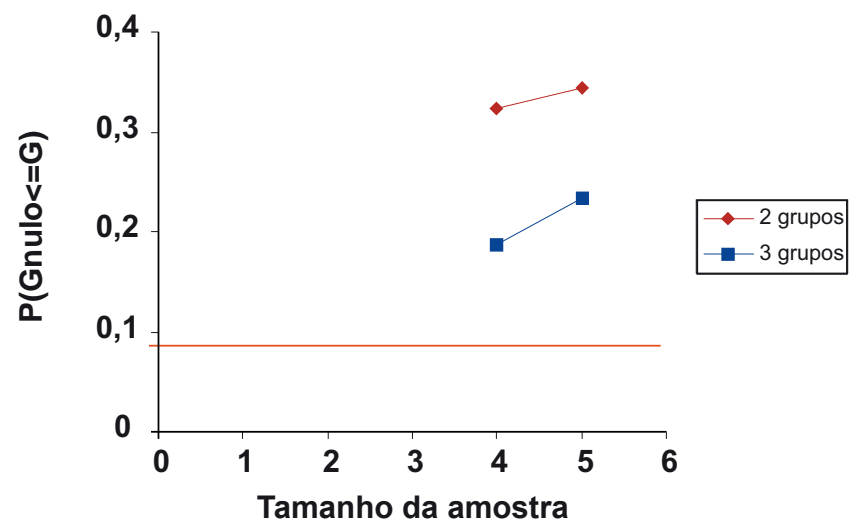

FIG. 1 - Avaliação da suficiência amostral e probabilidade de partição em 2 e 3 grupos, obtidos pela reamostragem.

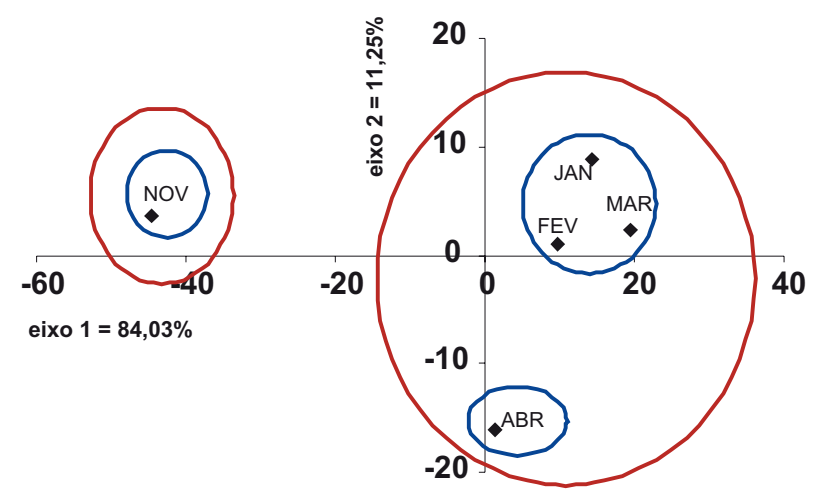

FIG. 2 - Diagrama de dispersão das unidades amostrais, que representam os meses de coleta das sementes de Bromus auleticus.

que os eixos 1 e 2 contém 95,3\% da variação, portanto, podese representar quase a totalidade das informações obtidas pela variação dos dados entre as unidades amostrais nestes dois eixos. Ou seja, os percentuais de contaminação pelos 15 gêneros de fungos observados estão bem representados na análise de ordenação.

O ponto que representa a coleta de novembro está bem distanciado dos demais, constituindo um único grupo. Assim, infere-se que a contaminação das sementes neste momento, quando as sementes ainda estavam presas à planta-mãe, era completamente diferente da contaminação apresentada nos meses de janeiro, fevereiro, março e abril, quando as sementes foram coletadas do solo. Observando-se a Tabela 1, verificase que principalmente duas variáveis contribuíram para esse resultado: a contaminação por Alternaria spp., que foi razoavelmente alta no mês de novembro e baixa ou nula nos demais meses; e a contaminação por Trichoderma spp., que foi nula em novembro e alta nos meses de janeiro em diante (média de 49,7\%).

Vários danos podem ser observados em sementes, ocasionados por Alternaria spp. (Lucca Filho, 2003). Altos percentuais de contaminação de aveia, trigo, cevada e triticale por espécies de Alternaria foram observados por Szigeti et al. (1995). Os autores comentaram que são necessárias investigações sobre as conseqüências dessa alta contaminação com relação à saúde animal, considerando essas sementes como alimento para ruminantes. Bovinos mantidos em pastagens de Brachiaria spp. estão propensos a sofrerem de fotossensibilização hepática, doença causada provavelmente pelo fungo Pithomyces chartarum (Schenk \& Schenk, 1983); esse patógeno, embora não tenha sido identificada a espécie, foi verificado neste estudo em baixo percentual em sementes da primeira coleta (na planta-mãe).

Observou-se também que muitos fungos presentes nas sementes, antes do degrane natural, desapareceram quando as sementes foram coletadas diretamente no solo (Tabela 1). Alguns desses fungos, como Fusarium spp. e Phoma spp., foram identificados como patogênicos em outras gramíneas (Skadsen \& Holn, 2004). Em trabalho realizado com outra gramínea forrageira, Brachiaria brizantha, Dias \& Toledo (1993) também verificaram incidência de Fusarium sp., Phoma sp. e Drechslera spp., comentando sua patogenicidade e a afinidade de Drechslera spp. por gramíneas.

O fungo Trichoderma tem a capacidade de sintetizar uma grande variedade de metabólitos que podem afetar outros organismos no mesmo nicho ecológico, funcionando como antibióticos. Além disso, tem grande capacidade de competição por nutrientes (Klein \& Eveleigh, 1998). Desta forma, a elevada contaminação por Trichoderma spp. nas sementes presentes no solo provavelmente explica a observação referida anteriormente, já que esse fungo não ocorreu antes do degrane natural, e apresentou uma alta correlação negativa com quase todos os demais fungos.

Em um trabalho realizado paralelamente a esse, foi avaliada a qualidade fisiológica de sementes oriundas das mesmas coletas, e obtiveram-se os seguintes resultados para germinação e dormência, respectivamente: novembro - 9\% e $82 \%$, janeiro - $23 \%$ e $68 \%$, fevereiro - $73 \%$ e $12 \%$, março - $49 \%$ e $29 \%$ e abril - 37\% e 30\%. Desta forma, constatouse que o máximo fluxo germinativo de Bromus auleticus ocorreu a partir do mês de fevereiro, quando a dormência é superada naturalmente, o que também foi verificado por Silva et al. (2002). O estado sanitário das sementes no momento da germinação é um aspecto fundamental a ser considerado. Trabalhando com quatro espécies de gramíneas, entre elas Bromus inermis, Schafer \& Kotanen (2003) verificaram que fungos fitopatogênicos são prejudiciais à germinação e estabelecimento de plantas no campo. Portanto, considerase que o fungo Trichoderma spp. pode ter uma função importante neste contexto, evitando a ocorrência de outros fungos maléficos em Bromus auleticus, na época de maior fluxo germinativo, os quais poderiam afetar a germinação e serem transmitidos pelas sementes.

Admitindo-se a formação de três grupos nítidos, observa-se na Figura 2 que o terceiro grupo seria formado exclusivamente pela coleta realizada no mês de abril. Esse distanciamento ocorreu principalmente em função da contaminação das sementes por Verticillium spp., verificada somente naquele momento. Esse fungo, possivelmente 
TABELA 1 - Percentagem de sementes de Bromus auleticus contaminadas por diferentes gêneros de fungos, em função da época de coleta

\begin{tabular}{|c|c|c|c|c|c|}
\hline Gênero do fungo & Novembro & Janeiro & Fevereiro & Março & Abril \\
\hline Alternaria spp. & 25,6 & 2,0 & 1,3 & 0,0 & 0,0 \\
\hline Phoma spp. & 6,4 & 14,5 & 0,0 & 0,0 & 0,0 \\
\hline Trichoderma spp. & 0,0 & 54,0 & 48,3 & 58,5 & 38,3 \\
\hline Verticillium spp. & 0,0 & 0,0 & 0,0 & 0,0 & 18,3 \\
\hline Bipolaris spp. & 2,4 & 0,0 & 0,0 & 0,0 & 0,0 \\
\hline Drechslera spp. & 1,1 & 0,0 & 0,0 & 0,0 & 0,0 \\
\hline Pithomyces spp. & 0,3 & 0,0 & 0,0 & 0,0 & 0,0 \\
\hline Cercospora spp. & 0,2 & 0,0 & 0,0 & 0,0 & 0,0 \\
\hline Epicoccum spp. & 0,8 & 0,0 & 0,0 & 0,0 & 0,0 \\
\hline Curvularia spp. & 0,4 & 0,0 & 0,0 & 0,0 & 0,0 \\
\hline Fusarium spp. & 2,2 & 3,0 & 2,7 & 0,0 & 3,3 \\
\hline Gerlachia spp. & 0,5 & 4,0 & 1,3 & 0,5 & 1,7 \\
\hline Cladosporium spp. & 0,6 & 0,0 & 0,3 & 0,0 & 0,0 \\
\hline Nigrospora spp. & 0,0 & 4,0 & 0,0 & 0,0 & 0,0 \\
\hline Septoria spp. & 0,0 & 0,0 & 1,7 & 0,0 & 0,0 \\
\hline
\end{tabular}

controlado por Trichoderma spp., também tem sido relatado como fitopatogênico em várias espécies (Ordentlich et al., 1990).

Assim, deduz-se que Trichoderma spp. possa cumprir uma função específica na regeneração natural de Bromus auleticus, atuando no sentido de preservar a sanidade das sementes durante sua vida no solo, e constituindo uma relação de mutualismo. É importante o entendimento destas relações entre organismos, as quais são fundamentais na manutenção do equilíbrio natural das populações e dos ciclos biológicos (Schafer \& Kotanen, 2003). Esse conhecimento pode contribuir na condução de um sistema produtivo, possibilitando o manejo de uma pastagem para maior persistência das espécies de interesse, porém de uma forma mais sustentável.

\section{AGRADECIMENTOS}

Gustavo M. Silva agradece ao Conselho Nacional de Desenvolvimento Científico e Tecnológico - CNPQ pela concessão de bolsa de estudo. Os autores agradecem aos estudantes e profissionais do Instituto Tecnológico da Campanha - INTEC, Bagé RS, pelo suporte material e humano para a realização dos testes de sanidade de sementes.

\section{REFERÊNCIAS BIBLIOGRÁFICAS}

BARCELLOS, J.O.J., PRATES, E.R., SILVA, M.D., MONTANHOLI, Y.R. \& WUNSCH, C. Sistemas pecuários no sul do Brasil - “zona campos”: tecnologias e perspectivas. Memorias, XIX Reunión de Grupo Técnico en Forrajeras del Cono Sur - Zona Campos. Sistemas de producción: caminos para una integración sustentable. Mercedes, Argentina. 2002. pp. 10-15.

BASKIN, C.C. \& BASKIN, J.M. Seeds: ecology, biogeography, and evolution of dormancy and germination. San Diego CA. Academic Press. 1998.

BOGGIANO, P. \& ZANONIANI, R.A. Producción de semilla de Bromus auleticus Trinius. Consideraciones generales. In: DIALOGO LVI - Los Recursos Fitogeneticos del Genero Bromus en el Cono Sur. PROCISUR, 2001. pp. 29-34.

DIAS, D.C.F.S. \& TOLEDO, F.F. Germinação e incidência de fungos em testes com sementes de Brachiaria brizantha Stapf. Scientia Agriculturae 50:68-76. 1993.

GARCIA, J. Variedades forrajeras. Jornada de Forrajeras, Colonia del Sacramiento. Anais, Centro de Investigaciones Agricolas “Alberto Boerger”, Estación Experimental La Estanzuela. Colonia del Sacramiento. 1988. pp. 1-3.

ISTA-INTERNATIONAL SEED TESTING ASSOCIATION. International Rules for Seed Testing. Seed Science and Tecnology 21:1-288, 1993.

KENKEL, N.C., JUHÁSZ-NAGY, P. \& PODANI, J. On sampling procedures in population and community ecology. Vegetation 83:195-207. 1989.

KLEIN, D. \& EVELEIGH, D.E. Ecology of Trichoderma. In: Kubicek, C.P. \& Harman, G.E. (Eds.) Trichoderma \& Gliocadium: basic biology, taxonomy and genetics. Taylor \& Francis Ltd. 1998. pp. 57-74.

LUCCA FILHO, O.A. Patologia de Sementes. In: Peske, S.T., Tosenthal, M.D. \& Rota, G.R. (Eds.) Sementes: Fundamentos Científicos e Tecnológicos. Ed. Universitária. 2003. pp. 225-282.

MARAÑON, T. Ecología de los bancos de semilla en el suelo: una revisión de estudios españoles. Pastos 25:3-25. 1995.

OLIVEIRA, J.C.P. \& MORAES, C.O.C. 1993. Distribuição da Produção e Qualidade de Forragem de Bromus auleticus Trinius. Pesquisa Agropecuária Brasileira 28:391-398. 1993.

ORDENTLICH, A., NACHMIAS, A. \& CHET, I. Integrated control of Verticillium dahliae in potato by Trichoderma harzianum and captan. Crop Protection 9:363-366. 1990.

PILLAR, V.D. MULTIV: Multivariate Exploratory Analysis, Randomization Testing and Bootstrap Resampling. User's Guide. 2001.

SCHAFER, M. \& KOTANEN, P.M. The influence of soil moisture on losses of buried seeds to fungi. Acta Oecologica 24:255-263. 2003.

SCHENK, M.A.M. \& SCHENK, J.A.P. Fotossensibilização hepatógena em bovinos: aspectos gerais. Comunicado Técnico Embrapa, n. 19. 1983.

SILVA, G.M., MAIA, M.S. \& MORAES, C.O.C. Dormência de sementes de cevadilha vacariana (Bromus auleticus Trinius) em função da época de colheita e do período de armazenamento. Revista Científica Rural 7:116-121. 2002. 
SKADSEN, R.W. \& HOLN, T.M. Use of Fusarium graminearum transformed with $g f p$ to follow infection patterns in barley and Arabidopsis. Physiological and Molecular Plant Pathology 64:45-53. 2004.
SZIGETI, G., NAGY, G., SZECSI, A. \& NEMETHNE, K.L. A mycological survey on feed cereals kept in stock of the crops of 1994. Magyar Allatorvosok Lapja 50:511-514. 1995.

Recebido 22 Maio 2006 - Aceito 10 Agosto 2007 - FB 6063 